\title{
ПЕРСПЕКТИВЫ ПРИМЕНЕНИЯ МАРКЕТИНГОВЫХ ПРИНЦИПОВ ПРИ РАЗВИТИИ ПРЕДПРИЯТИЙ ЛЕГКОЙ ПРОМЫШЛЕННОСТИ
}

\author{
Эргашев Алижон Ходжимаматович \\ $\mathrm{PhD}$, доиент \\ Ферганский государственный университет, \\ г.Фергана, Узбекистан
}

\begin{abstract}
Аннотация. В данной работе рассматриваются вопросы определения стратегии развития производства промышленных предприятий, указывается, что легкая промышленность является основой устойчивого развития производства товаров народного потребления, повышения уровня жизни населения. Даются рекомендации по подготовке и обоснованию долгосрочной стратегии развития производства легкой промышленности, анализируются внешнеэкономическая деятельность, структура экспорта и импорта, экспортный потенциал продукции, деятельность предприятий с иностранными инвестициями.

Annotation. This paper discusses the issues of determining the strategy for the development of production of industrial enterprises, it is indicated that light industry is the basis for the sustainable development of production of consumer goods, improving the standard of living of the population. Recommendations are given on the preparation and substantiation of a long-term strategy for the development of light industry production, foreign economic activity, the structure of exports and imports, the export potential of products, the activities of enterprises with foreign investment are analyzed.
\end{abstract}

Ключевые слова: предприятия, промышленность, экономика, продукция, конкуренция, импорт, экспорт

Key words: enterprises, industry, economics, products, competition, import, export

В конкурентной среде предприятия вынуждены постоянно реагировать на изменения рынка, искать инновационные решения и таким образом получать преимущество перед конкурентами. Изменения в конкурентной среде влияют не только на положение предприятия на рынке, но и на его внутренние процессы. В результате в последние годы все больше внимания уделяется эффективному и инновационному осуществлению операций внутри предприятия, уделяя при этом внимание внешним аспектам (производственной программе, качеству продукции и услуг и удовлетворенности клиентов) [2].

Оптимизация внутренних операций и эффективная организация бизнес-процессов важны для обеспечения конкурентоспособности на современных предприятиях.

Сегодня многие компании в Узбекистане активно пытаются создавать собственные модели бизнес-процессов или эффективно использовать существующие модели на практике. Многие предприятия и организации пытаются получить такой сертификат, который необходим для выхода на определенные рынки. При определении стратегии развития производства промышленных предприятий важно учитывать, какой сектор производства будет расширяться и, наоборот, в каком секторе произойдет сокращение (1-таблица) [3].

Коренные изменения в системе экономических отношений, основанных на рыночных отношениях, предъявляют новые требования к методам анализа и прогнозирования развития экономики, ее секторов, в том числе производства продукции легкой промышленности.

Мировой опыт показывает, что легкая промышленность является основой устойчивого развития производства товаров народного потребления, повышения уровня жизни населения. Рекомендуется подготовить и обосновать долгосрочную стратегию развития производства легкой промышленности в следующей последовательности [4]:

- первый этап: анализ состояния и уровня развития продукции легкой промышленности за годы независимости, выявление плюсов и минусов, проблем, неиспользованных резервов и возможностей, дисбалансов спроса и предложения;

- на втором этапе проводится оценка ресурсов, науки и технологий и человеческих ресурсов и условий для развития легкой промышленности, ситуации на внутреннем и внешнем рынках, основных характеристик новой техники и технологий для выявления специалистов для обучения и выращивания в нашем регионе;

Таблица 1

Структура отраслей производственных предприятий

\begin{tabular}{|c|c|}
\hline Сферы производства & Предприятия и организации \\
\hline Электроэнергетика & Тепловые и гидроэлектростанции, электрические и тепловые сети, котельные \\
\hline Топливо & Добыча нефти, угля нефтепереработка, газ \\
\hline Черная металлургия & $\begin{array}{c}\text { Добыча и переработка сырья из руды и шерсти, производство черных } \\
\text { металлов, труб и т. Д.. }\end{array}$ \\
\hline Цветная металлургия & $\begin{array}{c}\text { Производство алюминия, меди, олова, цинка, никеля, кобальта, драгоценных } \\
\text { металлов и алмазов и др. }\end{array}$ \\
\hline
\end{tabular}




\begin{tabular}{|c|c|}
\hline Химия и нефтехимия & $\begin{array}{c}\text { Производство минеральных удобрений, содовая промышленность, } \\
\text { химическое волокно и пряжа, синтетические смолы, лаки, пластмассы, } \\
\text { бытовая химия и т. д. }\end{array}$ \\
\hline $\begin{array}{l}\text { Машиностроение и } \\
\text { металлообработка }\end{array}$ & $\begin{array}{c}\text { Производство тяжелой, силовой и подъемной техники, автомобилей, кабелей, } \\
\text { лампочек, аккумуляторов. Производство насосов, оборудования и др. }\end{array}$ \\
\hline $\begin{array}{c}\text { Лесное хозяйство, обработка } \\
\text { древесины и целлюлозно-бумажное } \\
\text { производство }\end{array}$ & $\begin{array}{c}\text { Заготовка древесины, обработка древесины, лесохимическая } \\
\text { промышленность. Сверление металлов, фанеры, спичек. Производство } \\
\text { мебели, целлюлозы, бумаги и др. }\end{array}$ \\
\hline Строительные материалы & $\begin{array}{c}\text { Производство цемента, железобетонного оборудования, асбестоцементных } \\
\text { изделий, легких материалов и покрытий, сыпучих продуктов и др. }\end{array}$ \\
\hline Легкая промышленность & $\begin{array}{c}\text { Текстильная (включая хлопкоочистку, шелк, хлопок, шерсть, трикотаж, } \\
\text { изделия), кожаная, меховая и обувная промышленность и т. д. }\end{array}$ \\
\hline Продукты питания & $\begin{array}{l}\text { Консервы, хлеб и хлебобулочные изделия, сахар, кондитерские изделия, } \\
\text { макаронные изделия, масло, парфюмерия, косметика, алкоголь, вино, пиво, } \\
\text { фрукты и овощи, чай, табак, мясная и молочная промышленность и др. }\end{array}$ \\
\hline Другие отрасли & $\begin{array}{c}\text { Производство фарфора, стекла, микробиологии, муки и комбикормов, } \\
\text { полиграфии и других промышленных товаров. }\end{array}$ \\
\hline
\end{tabular}

- третий этап - определение конкретных направлений, целей, задач, разработка необходимых мер по определению долгосрочных перспектив развития легкой промышленности;

- на четвертом этапе разработка необходимых мер и механизмов для реализации легкой промышленности и определения ее социально-экономического статуса.

Анализ современного развития легкой промышленности направлен на определение баланса спроса и предложения на продукцию, основных идей, важных проблем, условий, направленных на увеличение производства и повышение его эффективности, работоспособность предприятий.

Анализ легкой промышленности на региональном и отраслевом уровне основан на разделении на межрегиональные страты, путем определения скорости вытеснения и пропорций в секторе. Технический и технологический уровень легкой промышленности характеризуется производством современных машин и оборудования, новыми технологиями и ноу-хау, конкурентоспособностью продукции на внешних рынках. Изучаются уровень использования основных производственных мощностей, обеспеченность рабочей силой деньгами и энергией, а также уровень эффективности использования ресурсов.

Финансовое состояние легкой промышленности характеризуется рентабельностью, долей предприятий в общем объеме производства, формами государственной поддержки и контроля, налогообложением, кредитованием, импортными и экспортными предложениями. Анализируются внешнеэкономическая деятельность, структура экспорта и импорта, экспортный потенциал продукции, деятельность предприятий с иностранными инвестициями.

Экономическая эффективность и конкурентоспособность легкой промышленности определяется как в разрезе отдельных регионов, отраслей, так и на примере отдельных продуктов. В ходе анализа выявляются проблемы, которые необходимо решить, и они служат основой для прогнозов.

Оценка конъюнктуры региональных рынков по основным товарам легкой промышленности проводится с помощью маркетинговых методов. Рекомендуется провести серию проверок региональных рынков. Прежде всего, товарные рынки формируются на основе выделенных товарных групп. Затем определение географических границ товарных рынков производится на основе анализа продуктов, поступающих на местные региональные рынки [5].

Границы рынка формируются на основе развития транспорта, грузовых тарифов и цен с использованием метода зонирования продукции легкой промышленности. Границы местного рынка проистекают из наличия конкурентов, т.е. производителей и ограниченных цен, определяющих рыночный спрос.

К факторам предложения товарных рынков относятся: доходы предприятий и населения, структура потребностей по группам доходов, затраты на производство и требования к качеству продукции, взаимозаменяемость продукции, система распределения населения (городское и сельское), грамотность и культура населения.

В группе факторов, определяющих текущее предложение на товарных рынках, следует учитывать следующее:

- производственная мощность;

- технологический уровень производства;

- подача ресурсов;

- уровень и качество стандартизации продукции;

- развитие рыночной инфраструктуры; 
- обеспечение транспортом;

- национальные и духовные ценности;

- формы и методы государственного управления.

На основе прогноза и анализа рыночного спроса изучается конъюнктура рынка основных товаров, их конкурентоспособность со странами СНГ и товаров на мировом рынке. Будут рассмотрены существующие иностранные конкуренты и определены меры по защите узбекских производителей.

При прогнозировании развития легкой промышленности следует обратить внимание на наличие разных форм собственности и их полное и эффективное использование в процессе приватизации, принимать меры по обеспечению региональных структурных сдвигов, в том числе: экспорт и импорт, межрегиональные, товарные группы, местные ресурсы, производственный потенциал. Особо важные направления находят отражение в удовлетворении спроса на товары народного потребления за счет улучшения использования финансовых ресурсов.

В процессе разработки предложения в различных сценариях и вариантах развития обосновываются следующие: структурные сдвиги в развитии и размещении производства, емкость товарного рынка и ценовые условия, инвестиционная активность, внедрение новой техники и технологий, защита окружающей среды, механизм регулирования.

При разработке сценариев развития рекомендуется предусматривать кардинально разные варианты развития с учетом реконструкции и технических аспектов, объемов инвестиций и привлечения иностранного капитала, роли государства в исследованиях и разработках и использовании сырьевого потенциала.

В ближайшем будущем структура модели развития легкой промышленности должна быть такой, чтобы развитие легкой промышленности обеспечивало динамичный рост отрасли, дальнейшее улучшение условий жизни населения, укрепление национальной безопасности и конкурентоспособности. Для этого необходимо решить социальные, макроэкономические, инвестиционные, структурные, институциональные финансовые и другие вопросы. Такие как:

1. Создание условий для повышения конкурентоспособности товаров. Это можно сделать за счет устранения дисбалансов в системе цен, снижения энергоемкости производства и так далее.

2. Создание благоприятных условий для увеличения внутреннего спроса. Это, прежде всего, сокращение бедности и сокращение неравенства в уровне жизни, повышение заработной платы за счет повышения производительности труда, эффективная организация занятости трудоспособного населения.

3. Расширение внутренних источников финансовых вложений будет достигаться за счет привлечения сбережений и увеличения доходов населения, а также за счет привлечения иностранных инвестиций в легкую промышленность.

4. Развитие конкурентного рынка товаров и услуг, повышение роли малого и среднего бизнеса в легкой промышленности.

Внешние условия развития включают прогноз развития мировой легкой промышленности в мировой экономике. Для того чтобы страна вышла на мировой рынок со своей продукцией, необходимо будет экспортировать свою продукцию на внешние рынки, расширять и улучшать ассортимент и вид экспортируемых товаров. Для этого потребуется финансовая поддержка со стороны государства (кредитование, гарантия экспортных контрактов и страхование). Роль выставок и ярмарок в увеличении экспорта также возрастет.

В легкой промышленности экономический рост в долгосрочной перспективе будет достигнут за счет повышения эффективности использования капитала и интеллектуальных ресурсов, расширения внутреннего спроса и емкости внутреннего рынка.

Развитие рынка легкой промышленности в ближайшем будущем будет происходить при следующих условиях [6]:

- расширение рынка хлопка и развитие инфраструктуры товарного рынка;

- улучшение конкурентной среды, создание равных условий на потребительском рынке;

- развитие финансовой инфраструктуры рынка промышленных товаров, финансовое оздоровление неплатежеспособных предприятий;

- улучшение материально-технической базы, экономических условий торговли.

Основными направлениями реконструкции структур легкой промышленности являются производство готовой продукции, то есть организация производства в соответствии с потребностями внутреннего рынка, а также глубокая переработка местного сырья.

При увеличении объемов производства готовой продукции на начальном этапе рекомендуется, например, шить недорогие товары для малообеспеченных покупателей, товары для детей и спецодежду для вооруженных сил.

Одним из других важнейших направлений является локализация производства в легкой промышленности и снижение зависимости от импортного сырья и материалов. 
Локализация остается необходимым условием восстановления экономики страны. Он обеспечивает не только независимость ресурса, но и его экспорт на мировой рынок, тем самым завоевывая прочную позицию в международном разделении труда, влияя на международную экономическую политику.

Узбекистан импортирует капроновые, лавсановые и вискозные волокна, льняную и объемную пряжу, химикаты, красители и более сотни видов материалов для обувной промышленности из других стран для производства товаров народного потребления и товаров легкой промышленности. В связи с этим акцент делается на сокращении объемов импортируемой продукции в Узбекистан и увеличении личного потребления и переработки хлопкового волокна.

Целью региональной политики в перспективе является создание широких организационных и экономических возможностей для равноправного развития всех регионов, создание условий для эффективного использования ими природного и экономического потенциала, создание факторов экономического роста, рациональная организация разделения труда, Государственная поддержка отсталых регионов, малых городов и сельской местности заключается в принятии мер поддержки.

В будущем территориальные и структурные изменения станут результатом этапов и реформ организационных изменений в общей экономике государства, их целей и задач.

\section{Список литературы:}

1. Шеер А.В. Бизнес-процессы. Основные понятия. Теория. Методы. - М.: Весть-МетаТехнология, 1999.

2. Stalk, G.; Evans, P.; Shulman, L. E.: Competing on Capabilities. In: Harvard Business Review, 70, 1992, 3-4, p.57-69.

3. Ортиков А. “Экономика промышленности”. (Учебник). - Т.: ТДИУ. 2004.

4. Эргашев, А.Х. (2016). Концепция маркетинга как способ максимизации прибыли предприятия.// Бюллетень науки и практики, (12 (13)).

5. Эргашев, А.Х., \& Уринбаева, Д.Х. (2019). Анализ использования маркетинговых стратегий в организации и конкурентоспособности маркетинговой деятельности дизайн-центра OOO «SHARQ LIBOSLARI». // Тенденции развития мировой торговли в XXI веке. (р.123-131).

6. Эргашев, А.Х. (2017). Программа воздействия маркетинговой стратегии на прибыль предприятий Ферганского региона. // Новый университет. Серия «Экономика и право», (1 (71)). 